\title{
Squamous Cell Carcinoma in a Left Periorbital Region in a Domestic Short Hair Cat: A Case Report
}

\author{
Tan Jun Jie ${ }^{1}$, Mohd Farhan Hanif Reduan ${ }^{*}$, Sabri Jasni ${ }^{1}$, Rumaizi Shaari ${ }^{2,3}$, Sujey Kumar \\ Rajendren $^{2}$, Nurshahirah Shaharulnizim², Nadiah Syuhada Roslan ${ }^{3}$, Intan Noor Aina \\ KamaruZaman ${ }^{1}$, Abd Rahman AZIZ ${ }^{1}$ \\ ${ }^{1}$ Department of Paraclinical Studies, Faculty of Veterinary Medicine, Universiti Malaysia Kelantan, Pengkalan \\ Chepa, 16100 Kota Bharu, Kelantan, Malaysia; ${ }^{2}$ Department of Clinical Studies, Faculty of Veterinary Medicine, \\ Universiti Malaysia Kelantan, Pengkalan Chepa, 16100 Kota Bharu, Kelantan, Malaysia; 3Universiti Malaysia \\ Kelantan Veterinary Clinic, Pengkalan Chepa, 16100 Kota Bharu,Kelantan, Malaysia.
}

\begin{abstract}
Squamous Cell Carcinoma (SCC) is a malignant tumour seen in common locations in cats such as non-pigmented skin, tonsils, tongue, mouth, oesophagus or lungs. In this case report, an eleven-years-old, intact female domestic short hair cat was presented to University Malaysia Kelantan Veterinary Clinic (KVUMK) with a complaint of a non-healing ulcerated wound at the left cranial frontal region of the head. Cytological evaluation of the impression smear found scanty of epithelial cells with erythrocytes. Histopathological examination of the wedge biopsy revealed epidermal hyperplasia, epidermal dysplasia, accentuation of rete ridge, keratosis and presence of keratin pearl. With the histopathological findings, squamous cell carcinoma was definitively diagnosed for this case. This case study aims to report a cutaneous SCC which occurred at the atypical site, the left periorbital region, with the discussion on the prognosis, chance of metastasis and the choice of treatment.
\end{abstract}

Keywords | Squamous cell carcinoma, Impression smear, Wedge biopsy, Keratin pearl, Epidermal hyperplasia

\begin{abstract}
Received | December 29, 2020; Accepted | January 19, 2021; Published | February 20, 2021
*Correspondence | Mohd Farhan Hanif Reduan, Department of Paraclinical Studies, Faculty of Veterinary Medicine, Universiti Malaysia Kelantan, Pengkalan Chepa, 16100 Kota Bharu, Kelantan, Malaysia; Email: farhan.h@umk.edu.my

Citation | Jie TJ, Reduan MFH, Jasni S, Shaari R, Rajendren SK, Shaharulnizim N, Roslan NS, Kamaruzaman INA, Aziz AR (2021). Squamous cell carcinoma in a left periorbital region in a domestic short hair cat: a case report. J. Anim. Health Prod. 9(2): 136-139.

DOI | http://dx.doi.org/10.17582/journal.jahp/2021/9.2.136.139

ISSN | 2308-2801
\end{abstract}

Copyright $($ C) 2021 Reduan et al. This is an open access article distributed under the Creative Commons Attribution License, which permits unrestricted use, distribution, and reproduction in any medium, provided the original work is properly cited.

\section{INTRODUCTION}

$\mathrm{S}_{\mathrm{n}}^{\mathrm{q}}$ quamous Cell Carcinoma (SCC) is a malignancy tumour which origins from squamous epithelium. It has been accounted for 15 to $48 \%$ among all the cutaneous neoplasia in cats (Ganta, 2018) while another study discovered that $15.2 \%(52 / 340)$ of skin tumours in cats was SCC (Miller et al., 1991). Nonetheless, it has been reported that squamous cell carcinoma is commonly found in cats, especially nasal planum, pinnae and eyelid of cats (Thomson, 2007). As reported by Murphy (2013), SCC comprises of $15 \%$ of feline skin tumours which is in accordance with the latter study which stated SCC accounts for 10 to $15 \%$ of all skin tumours in cats (Layne et al., 2016). However, SCC, in this case, is rather interesting as it involved the left cra- nial frontal region of the head, particularly left periorbital region of the head instead of common occurrence site of feline SCC such as the nasal planum. Thus, this case report focuses on a cutaneous SCC which occurred at the left periorbital region while discussing the prognosis, chance of metastasis and the choice of treatment.

\section{CASE DETAILS}

An 11 years old, intact female domestic shorthair cat which was presented to University Malaysia Kelantan Veterinary Clinic (KVUMK) with a complaint of a non-healing wound at the left cranial frontal region of the head. Upon the physical examination, there was an irregular, raised, non-healing ulcerated wound with a crusty border which 
was around $5 \mathrm{~cm}$ in diameter on the left cranial frontal region of the head. Meanwhile, unilateral enlargement of the left submandibular lymph node was detected. Complete Blood Count revealed normochromic, macrocytic anaemia with a moderate neutrophilia $\left(12.5 \times 10^{3} / \mu 1\right.$; reference value is 2.0 to $\left.8.0 \times 10^{3} / \mu \mathrm{l}\right)$. Cytological evaluation of the impression smear found scanty of epithelial cells with erythrocytes (Figure 1). The cat was tentatively diagnosed with SCC based on the clinical findings during the physical examination. Wedge biopsy was done and the excised tissue was immediately fixed in $10 \%$ buffered formalin. The fixed tissues were embedded into paraffin wax, sectioned with a $4 \mu \mathrm{m}$ thickness and stained with Haematoxylin and Eosin (H\&E) as previously described (Reduan et al., 2020)

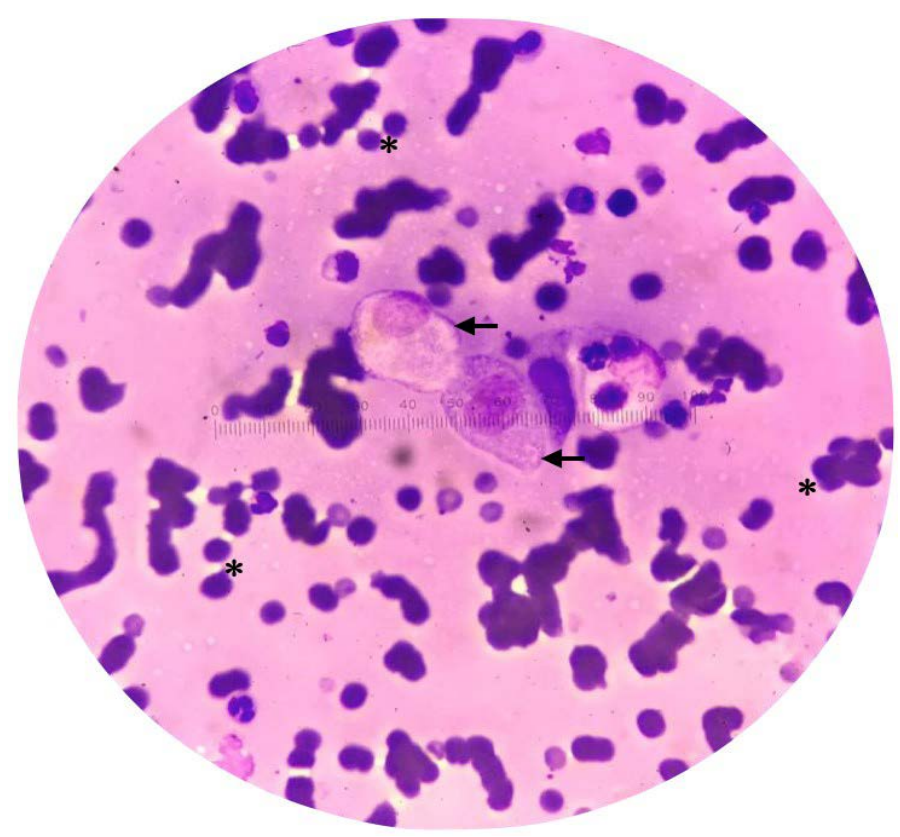

Figure 1: Cytology of impression smear showing erythrocyte $\left(^{*}\right)$ and epithelial cells (arrow). (Diff-Quik stain, $\mathrm{x} 40)$.

\section{RESULT AND DISCUSSION}

Grossly, the lesion appeared to be irregular, raised and non-healing ulcerated wound at the left cranial frontal region of the head, particularly the periorbital area. This clinical finding was in accordance with Valenciano and Cowell (2019), who stated Squamous Cell Carcinoma (SCC) affects commonly pinnae, nasal planum and eyelid in cats, especially white-furred cats. In this case, SCC occurred at the atypical site, which is the left periorbital region of the cat.

In this case, the impression smear revealed scanty of epithelial cells with erythrocytes which less resemble SCC cytologically. Nonetheless, cytological evaluation of a typical SCC case should show polygonal to round epithelial cells with marked anisocytosis and anisokaryosis. The neo- plastic cells often manifest bright sky-blue and hyalinized cytoplasm (Burton, 2008). Meanwhile, epithelial cells may show individually or occur in sheets and clusters with anisocytosis, mild anisokaryosis with cornifying cytoplasm (Valenciano and Cowell, 2019). Nonetheless, it is difficult to examine the impression smear cytologically to diagnose SCC as the presence of inflammatory cells and erythrocytes might hinder the neoplastic cells from dysplastic or hyperplastic cells.

The two main distinct forms of SCC are Actinic Keratosis (AK) and Bowen in situ carcinoma (BISC), where this case is classified as AK due to its characteristics of less hyperplastic and less deeply affected hair follicles (Favrot et al., 2009). For the histopathological evaluation of the excised tissue through wedge biopsy, it revealed epidermal hyperplasia, epidermal dysplasia, keratosis, accentuation or rete ridge and presence of keratin pearl (Figure 2 and Figure 3). As the epithelial hyperplasia progresses, the epithelial lining extends and projects into the underlying connective tissue of the skin, which is known as rete accentuation. Meanwhile, the presence of keratin pearls (Figure 4) is suggestive of SCC but it is not definitive as it has been reported that the keratin pearls were not found in some lesions of SCC in cats (Conceição et al., 2007). Meuton (2016) reported that early neoplastic lesions, which is also known as actinic keratosis, express the histological features of epidermal hyperplasia, hyperkeratosis, parakeratosis, acanthosis, epidermal rete accentuation, and keratinocyte dysplasia where most of the histological features fulfil the histological findings of this case. Squamous Cell Carcinoma (SCC) can be definitely diagnosed histologically once distinctive features of SCC such as keratin pearl and intercellular bridge are identified. However, both keratin pearl and intercellular bridge can only be observed whenever the SCC is still classified as well-differentiated neoplasm (Meuton, 2016).

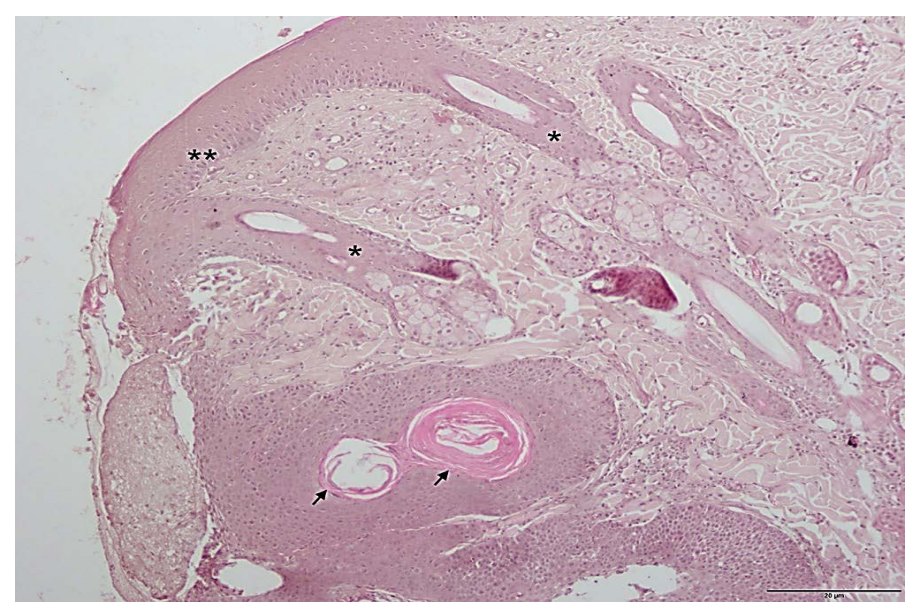

Figure 2: Histopathologic section of the excised tissue: rete accentuation $\left(^{*}\right)$, epidermal hyperplasia $\left(^{* *}\right)$ and keratin pearl (arrow). (H\&E, 10x). Scale; $5 \mu \mathrm{m}$. 


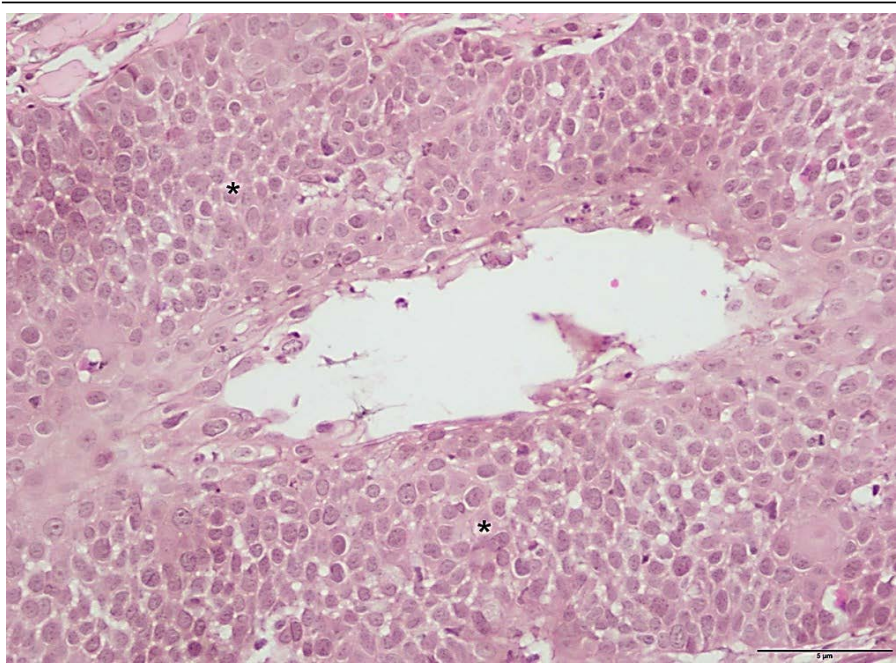

Figure 3: Histologic section of the excised tissue showing epidermal dysplasia (*). (H\&E stain, 40x). Scale; $5 \mu \mathrm{m}$.

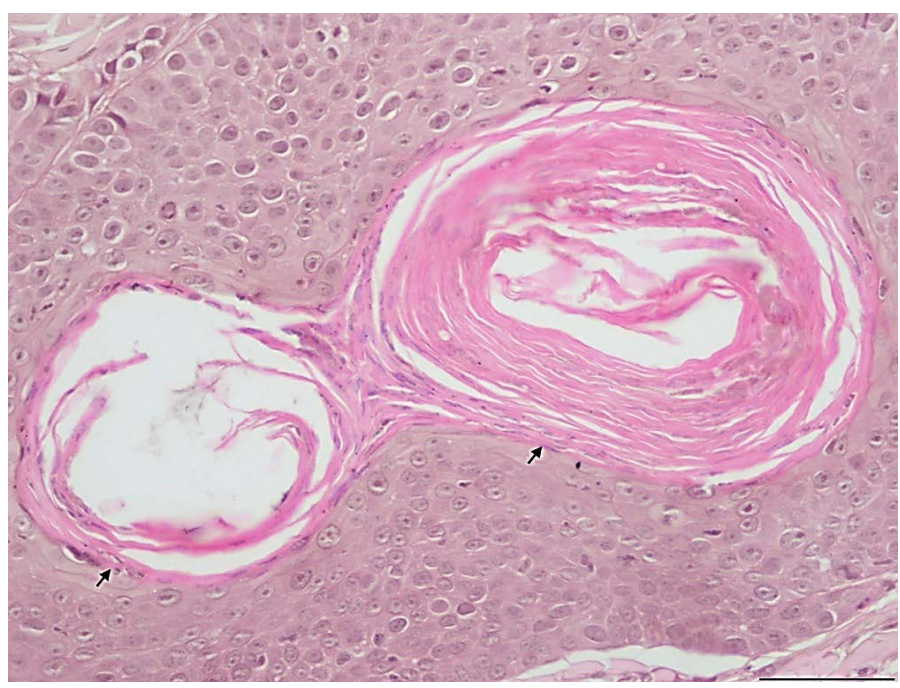

Figure 4: Histologic section of the excised tissue showing keratin pearl (arrow). (H\&E, 40x). Scale; $5 \mu \mathrm{m}$.

Based on the guideline of SCC grading system by Meuton (2016), this case was suited to be staged as SCC grade 2 as it showed epithelial cells with less eosinophilic cytoplasm, moderate anisokaryosis and hyperchromatism. In SCC grade 2, fewer keratin pearls are observed and the intercellular bridge is difficult to be identified while showing prominent invasion of neoplastic cells into the connective tissue which is known as an accentuation of epidermal rete (Meuton, 2016). Histological findings of this case completely fulfil the criteria of SCC grade 2.

Prognosis of feline cutaneous SCC is good as SCC is mostly a locally invasive neoplasm that seldom undergoes metastasis. As reported, SCC seldom metastasizes but continues to advance into cancerous ulcerations that lead to painful and unhealing injury (Lana et al., 1997). As stated by Murphy (2013), the prognosis for nasal planum SCC is good with a $71.42 \%(5 / 7)$ of the cases after complete resection of the nasal planum. On the other hand, it had been reported that tumour resection of SCC by orbitectomy provided localized disease-free interval of more than 1 year in the majority of the cases which was comprised of more than $50 \%$ of the patients and $36.7 \%$ of the cases $(11 / 24)$ showed regrowth of the tumour in the periorbital region after surgical resection wit orbitectomy (O'brien et al., 1996).

As mentioned earlier, surgical resection of the cutaneous Squamous Cell Carcinoma (SCC) will be the best choice of surgical treatment of this case. A clean surgical resection of the cutaneous SCC should be done with a lateral margin of $1 \mathrm{~cm}$ and deep margin of $0.5 \mathrm{~cm}$ to $1 \mathrm{~cm}$, which is in accordance with Murphy (2013). Cryosurgery is an alternative treatment to cutaneous SCC as well (Murphy, 2013), with $17 \%(17 / 102)$ of the cases were reported to have a recurrence with a median of 6.6 months after the cryosurgery treatment (Clarke, 1991). Last but not least, Fox (1995) stated that both surgical resection of and cryosurgery both are the best choice of treatment for cutaneous SCC provided that the cutaneous SCC is not metastasized. Therefore, cryosurgery might be a better choice of treatment for this case as compared to surgical resection due to a limited deep margin for surgical resection. A hypofractioned radiation protocol of radiation therapy on SCC had been reported as an alternative treatment against cutaneous SCC in cats (Cunha et al., 2010). Meanwhile, a radiation therapy of Strontium 90 had been documented as a successful treatment for feline cutaneous SCC (Fox, 1995).

\section{CONCLUSION}

In conclusion, the diagnosis of Squamous Cell Carcinoma (SCC) would be the best using histopathological evaluation of the excised tissues through wedge biopsy. Squamous Cell Carcinoma (SCC) is normally found in cats with predilection site of the oral cavity and nasal planum. In most cases, SCC exhibits the characteristics of malignancy and resistance by expressing a high reoccurrence rate despite having surgical excision and chemotherapy.

\section{ACKNOWLEDGEMENT}

The author would like to acknowledge Veterinary Officers of KVUMK and laboratory staff of Clinical Pathology \& Histopathology, Faculty of Veterinary Medicine, University Malaysia Kelantan for their technical assistance during the handling process of this case.

\section{CONFLICT OF INTEREST}

The authors declare that there is no conflict of interest. 


\section{AUTHORS CONTRIBUTION}

All authors contributed equally and approved the final manuscript.

\section{REFERENCES}

-Burton A (2018). Cutaneous and Subcutaneous Lesions. In: Clinical Atlas of Small Animal Cytology. New Jersey: Wiley Blackwell.

- Clarke RE (1991). Cryosurgical treatment of feline cutaneous squamous-cell carcinoma. Aust. Vet. Pract. 21(3): 148-153.

- Conceição LG, Camargo LP, Costa PRS, Kuwabara DA, Fonterrada CO (2007). Squamous cell carcinoma (Bowen $\mathrm{s}$ disease) in situ in three cats. Arq. Bras. Med. Vet. Zoo. 59(3): 816-820. https://doi.org/10.1590/S010209352007000300039

- Cunha SC, Carvalho LAV, Canary PC, Reisner M, Corgozinho KB, Souza HJ, Ferreira AMR (2010). Radiation therapy for feline cutaneous squamous cell carcinoma using a hypofractionated protocol. J. Feline. Med. Surg. 2010: 306313. https://doi.org/10.1016/j.jfms.2009.10.005

- Favrot C, Welle M,Heimann M, Godson DL, Guscetti F (2009). Clinical, histologic, and immunohistochemical analyses of feline squamous cell carcinoma in situ. Vet. Pathol. 46(1): 25-33. https://doi.org/10.1354/vp.46-1-25

- Fox LE (1995). Feline cutaneous and subcutaneous neoplasms. Vet. Clin. N. Am. Small. 25(4): 961-979. https:// doi.org/10.1016/S0195-5616(95)50137-8

- Ganta C (2018). Cutaneous Squamous Cell Carcinoma in Cats: Associated Factors. Retrieved from https://www.ksvdl.org/ resources/news/diagnostic_insights/march2018/squamous. html.

- Lana SE, Ogilvie GK, Withrow SJ, Straw RC, Rogers KS
(1997). Feline cutaneous squamous cell carcinoma of the nasal planum and the pinnae: 61 cases. J. Am. Anim. Hosp. Assoc. 33(4): 329-332. https://doi.org/10.5326/1547331733-4-329

-Layne EA, Graham M (2016). Cutaneous squamous cell carcinoma manifesting as follicular isthmus cysts in a cat. J. Feline. Med. Surg. Open. Rep. 2(1). https://doi. org/10.1177/2055116915625356.

- Meuten DJ (2016). Epithelial and Melanocytic Tumours of the Skin. In: Tumors in domestic animals. North Carolina: John Wiley \& Sons.

-Miller MA, Nelson SL, Turk JR, Pace LW, Brown TP, Shaw DP, Fischer JR, Gosser HS (1991). Cutaneous neoplasia in 340 cats. Vet. Pathol. 28(5): 389-395. https://doi. org/10.1177/030098589102800506

-Murphy S (2013). Cutaneous squamous cell carcinoma in the cat: current understanding and treatment approaches. J. Feline. Med. Surg. 15(5): 401-407. https://doi. org/10.1177/1098612X13483238

- O'brien MG, Withrow SJ, Straw RC, Powers BE, Kirpensteijn JK 1996. Total and partial orbitectomy for the treatment of periorbital tumors in 24 dogs and 6 cats: a retrospective study. Vet Surg. 25(6): 471-479. https://doi.org/10.1111/ j.1532-950X.1996.tb01445.x

-Reduan FH, Shaari RM, Sayuti NSA, Mustapha NM, Bakar MZA, Sithambaram S, Hamzah H (2020). Acute and subacute dermal toxicity of ethanolic extract of Melastoma malabathricum leaves in Sprague-Dawley rats. Toxicol. Res. 2020: 1-8. https://doi.org/10.1007/s43188-019-00013-5

-Thomson M (2007). Squamous cell carcinoma of the nasal planum in cats and dogs. Clin. Tech. Small Anim. Pract. 22(2): 42-45. https://doi.org/10.1053/j.ctsap.2007.03.002

-Valenciano AC, Cowell RL (2019). Cowell and Tyler's Diagnostic Cytology and Hematology of the Dog and CatE-Book. Elsevier Health Sciences. 